\title{
Bolus calculator in personal insulin pumps - advantages, differences and practical tips
}

\section{ABSTRACT}

The widespread use of personal insulin pumps in the treatment of type 1 diabetes has significantly improved the effects of therapy. Better metabolic control of diabetes, but also increased comfort of life and professional opportunities have been achieved. One of the functions that increased the effectiveness of insulin therapy using a personal insulin pump is the bolus calculator. The bolus calculator function allows the user to dose their insulin more accurately before meals and to correct hyperglycaemia. The bolus calculator algorithms in insulin pumps of individual manufacturers differ in the way they calculate the correction dose and the amount of so-called active insulin. Consequently, with the same treatment parameters, individual bolus calculators may offer a different dose of insulin. Understanding the principles of the bolus calculator by therapeutic team members and patients is very important for proper diabetes education and diabetes management. (Clin Diabetol 2020; 9; 4: 253-258)

Key words: type 1 diabetes, personal insulin pump, bolus calculator, active insulin

Address for correspondence:

dr n. med. Andrzej Gawrecki

Uniwersytet Medyczny im. Karola Marcinkowskiego w Poznaniu

Oddział Diabetologii i Chorób Wewnętrznych

Szpital Miejski im. Franciszka Raszei

ul. Mickiewicza 2, 60-834 Poznań

Tel: 6182245270

e-mail: pompainsulinowa@wp.pl

Translation: lek. Małgorzata Kamińska

Clinical Diabetology 2020, 9, 4, 253-258

DOI: $10.5603 /$ DK.2020.0028

Received: 21.06 .2020

Accepted: 29.06.2020

\section{Introduction}

People suffering from type 1 diabetes should be treated with intensive functional insulin therapy from the very beginning. This approach is based on the administration of variable doses of short-acting insulin (bolus insulin) and long-acting insulin (basal insulin). This method of treatment can be implemented using pen injectors or personal insulin pump (PIP). Precise adjustment of insulin doses to the daily activities of patients is much easier with the use of PIP, because continuous subcutaneous insulin infusion (CSII) allows for better mimicking of the physiological secretion of insulin. This method of insulin administration improves metabolic control of diabetes, reduces the incidence of hypoglycaemia and improves the quality of life of patients with type 1 diabetes [1-4]. One of the most important features of PIP is a bolus calculator (BC). It is recommended to use $\mathrm{BC}$ from the beginning of therapy [5]. This facilitates the precise estimation of insulin bolus [6, 7]. In addition, BC provides very important information about the amount of active insulin in the body, so-called insulin-on-board (IOB). This parameter takes into account insulin boluses delivered within the last few hours and prevents administration of a too high correction dose [8]. Studies have also shown that the use of $B C$ improves glycaemic control in patients by reducing blood glucose variability, i.e. lowering the low blood glucose index (LBGI) and high blood glucose index (HBGI) parameters [9]. Benefits of using PIP and $B C$ are possible in well-educated patients who understand the principles of its function [10].

\section{Bolus calculator in various models of insulin pumps}

Bolus calculators can be integrated in insulin pumps, stand-alone devices or software applications: 
- bolus calculator integrated in PIP (Medtronic): Minimed 715, Minimed 722, Minimed VEO, Minimed 640G [11];

- external bolus calculator - a remote control that functions as a blood glucose meter (Roche): AccuChek Spirit Combo, Accu-Chek Solo [12];

- bolus calculator in the mylife ${ }^{\mathrm{TM}}$ App (Ypsomed) that can be installed on a mobile device, e.g. a smartphone: YpsoPump - one-way communication between PIP and the BC application; data from PIP are automatically sent to the mobile device; bolus administration via the application is not possible [13].

\section{Basic parameters common \\ to all bolus calculators}

The basic element of intensive functional insulin therapy is the systematic use of a well-programmed bolus calculator, taking into account the individual needs of the patient. The parameters that the bolus calculator takes into account include [14]:

- insulin-to-carbohydrate ratio (ICR). As in the case of injection therapy, it is necessary to determine ICRs for each time interval during the day, i.e. what dose of insulin will cover the consumption of 1 carbohydrate exchange ( $1 \mathrm{CE}=10 \mathrm{~g}$ of carbohydrates) or how many grams of carbohydrates compensates for 1 unit of insulin. The user can select how to enter carbohydrates into the $B C$, with the exception of the $B C$ on the YpsoPump, which can only be programmed in grams, not KE. Bolus calculators give the users greater flexibility in establishing insulin-to-carbohydrate ratios and precise insulin dosing with accuracy of 0.1 unit. Accuracy of less than 0.1 unit may be achieved with some pump models, but this is not usually the case in clinical practice.

Examples of programming the insulin-to-carbohydrate ratios:

1 unit/CE or $10 \mathrm{~g}$ of carbohydrates per 1 unit of insulin,

1.4 units/CE or $7 \mathrm{~g}$ of carbohydrates per 1 unit of insulin;

- insulin sensitivity (correction factor) - this parameter determines how much blood glucose will decrease (in $\mathrm{mg} / \mathrm{dL}$ ) after administration of 1 unit of insulin. For most adult patients the values of this parameter are in the range of $30-60 \mathrm{mg} / \mathrm{dL}$ and may be different in particular times of the day;

- target blood glucose - this is the desired blood glucose value at the time of bolus administration. Depending on the $\mathrm{BC}$, it is possible to set a sin-
Correction factor $1 \mathrm{U}$ per $40 \mathrm{mg} / \mathrm{dL}$

Target blood glucose $100 \mathrm{mg} / \mathrm{dL}$

Blood glucose $80 \mathrm{mg} / \mathrm{dL}$

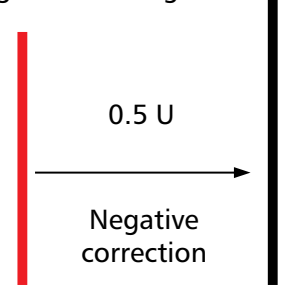

Blood glucose $120 \mathrm{mg} / \mathrm{dL}$

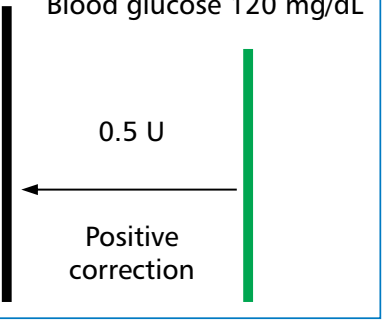

Figure 1. Calculation of a negative or positive correction by the bolus calculator for a sensitivity factor of $1 \mathrm{U}$ per $40 \mathrm{mg} / \mathrm{dL}$

gle blood glucose value or target range, e.g. 80$-120 \mathrm{mg} / \mathrm{dL}$. The settings determine the amount of the correction bolus and the so-called negative correction, i.e. reduction of the meal bolus in the event of blood glucose levels below the target value. Target blood glucose should be based on clinical status, current metabolic control of diabetes, and patient expectations (Fig. 1). This parameter should not be confused with the postprandial blood glucose target, which is not included in BC programming.

\section{Differences in programming target blood glucose depending on PIP model}

Insulin pumps produced by Medtronic and Roche are programmable for either a single target blood glucose value or a target range. The difference between them is a different algorithm for calculating the correction bolus. Medtronic's BC uses the border values of the set range as glycaemic targets. For example, when target blood glucose of $80-120 \mathrm{mg} / \mathrm{dL}$ is programmed, then if a hypoglycaemia occurs, the $B C$ will calculate a negative correction for the target blood glucose of $80 \mathrm{mg} / \mathrm{dL}$, and in the case of hyperglycaemia, it will use $120 \mathrm{mg} / \mathrm{dL}$ as the target blood glucose. For Roche's BC, the correction bolus is always computed to the middle value of the range, i.e. with a blood glucose target of 80-120 mg/dL - for both hypo- and hyperglycaemia, it will choose $100 \mathrm{mg} / \mathrm{dL}$ as the desired value (Fig. 2). Users of the bolus calculator in YpsoPump can only set up a single blood glucose value; there is no option to program a wider range.

Active insulin time (insulin on board) - determines how long the BC algorithm will include bolus insulin. On this basis, PIP informs about the amount of the active insulin that is already in the body. This feature is designed to prevent too much insulin being delivered to correct hyperglycaemia while insulin from previous 


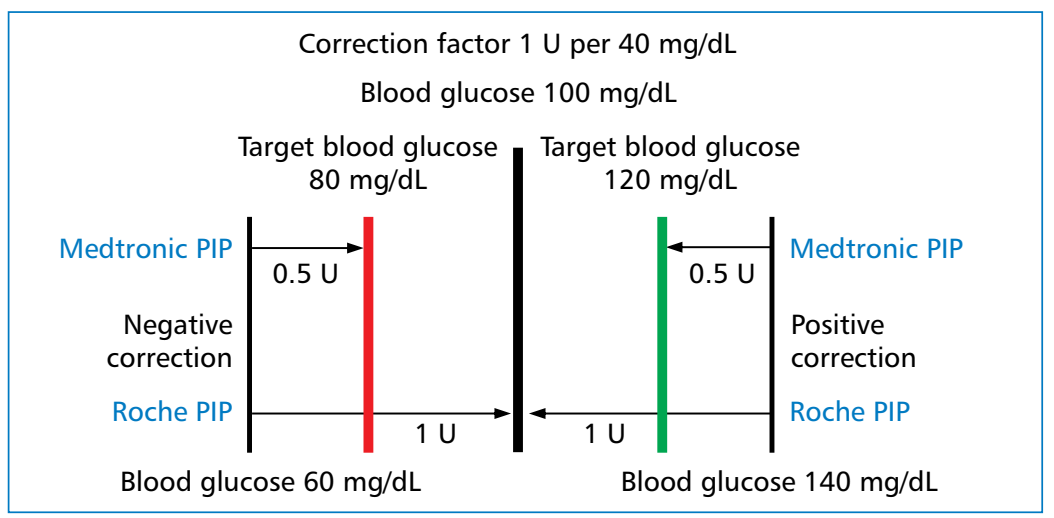

Figure 2. Calculations of the correction dose of insulin by the bolus calculator depending on the manufacturer; PIP - personal insulin pump



Figure 3. Calculating insulin acting time/insulin-on-board depending on the manufacturer; PIP — personal insulin pump

boluses is still working. Therefore, active insulin feature reduces only the dose of the correction bolus, not the meal bolus. An exception is one of the two available $\mathrm{BC}$ algorithms in the mylife ${ }^{\mathrm{TM}} \mathrm{App}$, where this feature reduces both the correction dose and mealtime bolus. The choice of algorithm in the mylife ${ }^{\mathrm{TM}}$ App depends on the patient's preferences and the recommendations of the diabetologist. In any bolus calculator, the amount of active insulin and the rate at which it is decreasing is directly related to the programmed insulin acting time. Information about the amount of active insulin is available, depending on the PIP model, from the pump screen, remote control or app.

The algorithm that calculates the amount of active insulin differs between manufacturers. The BC in PIPs by Medtronic and YpsoMed considers both mealtime and correction bolus insulin to be active insulin. In Roche's insulin pump, active insulin comes only from correction boluses (Fig. 3).
The BC algorithm in Accu-Chek Spirit Combo and Accu-Chek Solo takes into account additional parameters along with the insulin acting time, which include: - meal rise - shows the maximum value by which blood glucose can rise after a meal without prompting a correction bolus;

- offset time - is period of time after a bolus administration until significant reduction in blood glucose begins. This is the first phase of the period known as insulin acting time;

- snack size - is the amount of carbohydrates that is not considered as a standard meal and the BC does not activate the meal rise, so that the blood glucose increase reading is recorded and prompts a correction bolus.

The manufacturer's educational materials explain the bolus calculator algorithm using a trapezoid diagram, where the longer base of the trapezoid is "insulin acting time", the shorter base is "offset time", and 
the height of the trapezoid is the "meal rise' parameter. Increasing/decreasing these parameters causes a corresponding increase/decrease in the trapezoidal area, which in practice means a reduced/increased correction dose of insulin at the time of postprandial hyperglycaemia.

\section{Clinical aspects of the bolus calculator}

Programming the $\mathrm{BC}$ in accordance with the principles of intensive functional insulin therapy requires extensive experience of the doctor and good cooperation with the patient. Proper blood glucose selfmonitoring using a blood glucose meter or continuous glucose monitoring is essential. The bolus calculator is especially appreciated by professionally active people because it saves time and improves postprandial blood glucose levels [15].

Typically when setting the $\mathrm{BC}$, the following parameters must be determined individually for each patient:

- insulin-to-carbohydrate ratio (ICR) - to initially determine this parameter, the rule of 400 should be used. Dividing 400 by the total daily insulin dose (DDI) gives the number of grams covered by $1 \mathrm{U}$ of insulin, e.g. 400 : $40 \mathrm{U}=10 \mathrm{~g} / \mathrm{U}$. It is an average value for the whole day. Insulin sensitivity changes during the day, so ICR in the morning hours can be up to $50 \%$ higher than that calculated and it can be lower in the midday hours;

- insulin sensitivity (correction factor) - one recommended approach is the 1800 rule. Dividing 1800 by the DDI gives the average blood glucose reduction after administration of $1 \mathrm{U}$ of insulin, e.g. 1800: $40 U=45 \mathrm{mg} / \mathrm{dL}$. Insulin sensitivity shows high individual and daily variability. The highest insulin sensitivity is observed in the first half of the night and in the middle of the day, and it is lower in the morning and during afternoon and evening hours;

- target blood glucose - it is preferable that the daytime values of this parameter should be lower than the nighttime values, because the perception of hypoglycaemia at night is impaired. In clinical practice, these values are in the range of 80-120 $\mathrm{mg} / \mathrm{dL}$. In some clinical situations, this parameter requires individual adjustment, e.g., in pregnant women with diabetes, the recommended target blood glucose at night and before meals is 70$-90 \mathrm{mg} / \mathrm{dL}$. Patients with known proliferative retinopathy and chronic hyperglycaemia require higher glycaemic targets, e.g., 120-150 mg/dL. Similarly, patients with hypoglycaemia unawareness or have fear of hypoglycaemia will need higher blood glucose levels;
- active insulin time (insulin on board) - in clinical practice, active insulin time/IOB in adults is programmed for 3-4 hours. It depends on the size of the bolus administered, and for boluses greater than 10-15 units, this time can be extended to 5 hours. During pregnancy, when postprandial glucose control is very important and frequent correction boluses are required, the insulin acting time is usually programmed for 3 hours. Some pump models offer the option of programming the insulin acting time with an accuracy of 15-30 minutes. Information about the amount of active insulin has a significant impact on the therapeutic decisions made by the patient [16]. A special situation is when hyperglycaemia persists for a long time and the patient administers correction boluses repeatedly. Active insulin function then reduces the risk of hypoglycaemia due to the simultaneous action of several boluses. In everyday life, decisions about the correction of hyperglycaemia just before going to bed are a frequent problem. The BC allows the user to calculate a safe dose of a correction bolus, and data on the amount of active insulin makes it easier to decide on the consumption of an additional portion of carbohydrates.

Bolus insulin must be taken into account during physical activity. The bolus calculator is a tool that allows the user to adjust the amount of active insulin to their training in a repeatable and precise manner [17]. The effect of physical activity is very individual and only on the basis of the patient's own experience it is possible to determine what amount of active insulin is appropriate for him or her. Too much active insulin requires the consumption of carbohydrates. This information is especially valuable when the patient plans to disconnect the insulin pump, as too little active insulin can cause a significant increase in blood glucose and lead to ketosis.

The specific features of BC in the Accu-Chek Spirit Combo System are presented in Table 1. The initial BC settings were proposed by a group of experts of the Diabetes Poland (PTD) (Table 1) [18]. These settings require clinical verification and are only a starting point for the use of $B C$. The same $B C$ programming principles apply to the Accu-Chek Solo.

\section{Correct use of a bolus calculator by patients}

Optimal use of a BC requires the patient to enter information about the amount of carbohydrate consumed and the current blood glucose level. It is necessary to accurately count the carbohydrate consumed, which is entered into the calculator in grams 
Table 1. Proposed bolus calculator settings in the Accu-Chek Combo system (modified after [18])

\begin{tabular}{|c|c|c|c|c|c|c|}
\hline \multirow[t]{2}{*}{ Parameter (available range) ${ }^{1}$} & \multirow[t]{2}{*}{ Units } & \multicolumn{5}{|c|}{ Individual settings } \\
\hline & & $1-6$ years & $7-11$ years & $12-18$ years $^{2}$ & Adults & Women \\
\hline Carbohydrate exchange $\left(\mathrm{KE}^{*}\right)$ & & KE & KE & KE & KE & KE \\
\hline Insulin sensitivity, units/1 KE (0.1-24) & $\mathrm{U} / \mathrm{KE}$ & The 400 rule & The 400 rule & The 400 rule & The 400 rule & The 400 rule \\
\hline $\begin{array}{l}\text { Insulin sensitivity, blood glucose reduction } \\
\text { by } 1 \text { unit of insulin }\end{array}$ & & $\begin{array}{l}\text { The } 1800 \\
\text { rule }\end{array}$ & $\begin{array}{l}\text { The } 1800 \\
\text { rule }\end{array}$ & $\begin{array}{l}\text { The } 1800 \\
\text { rule }\end{array}$ & $\begin{array}{l}\text { The } 1800 \\
\text { rule }\end{array}$ & $\begin{array}{l}\text { The } 1800 \\
\text { rule }\end{array}$ \\
\hline \multicolumn{7}{|l|}{ Bolus advice options } \\
\hline Meal rise $(50-200)$ & $\mathrm{mg} / \mathrm{dL}$ & 80 & 80 & 50 & 50 & 50 \\
\hline Snack size (0-2.4 KE) & KE & $0.5-1.0$ & $1.0-1.5$ & 2 & 2 & 2 \\
\hline Insulin acting time (1.5-8 hours) & $\mathrm{h}$ & 3 & 3 & 3 & $3-5^{3}$ & $3-4^{3}$ \\
\hline Offset time (from $45 \mathrm{~min}$ to blood glucose reduction) & $\mathrm{h}$ & 1.5 & 1.5 & 1 & 1 & $3 / 4-1^{4}$ \\
\hline
\end{tabular}

${ }^{1}$ Definitions of bolus calculator features are presented in the respective operating manual

2Parameter settings can be applied as for adults

${ }^{3}$ Depending on bolus size, $3 \mathrm{~h}<10 \mathrm{U}, 4 \mathrm{~h}<10-20 \mathrm{U}, 5 \mathrm{~h}>20 \mathrm{U}$

${ }^{4}$ Depending on the trimester of pregnancy

${ }^{*}$ Germ. Kohlenhydrateinheit

or carbohydrate exchanges. Blood glucose values are sent wirelessly from the glucose meters to the pump, or they can be entered manually. Only for the Accu-Chek Performa Combo remote control, which is also a glucometer, the blood glucose results cannot be entered manually. After the measurement, blood glucose is stored in the remote control for 5 minutes.

The insulin dose proposed by the BC on the basis of the above parameters will not always be adequate to the current clinical situation [19]. This also applies to the patient's decision to choose a combination or extended bolus type. A well-educated PIP user will not always agree with BC's suggestion. For example, when planning physical exercise within 2 hours of a meal, the patient should reduce the calculated bolus by $30-50 \%$ in order to avoid hypoglycaemia. Conversely, increasing the bolus dose will be required during periods of increased insulin requirements. These includes situations that are very common in everyday life, such as infections, limited physical activity, stress or eating meals with a high glycaemic index. Then, the standard BC settings do not match the actual insulin requirement. The bolus calculator also does not take into account the variable rate of insulin absorption, gastric emptying, or the qualitative composition of the meal.

It is worth noting that repeated non-compliance with the $\mathrm{BC}$ may indicate the need to modify its settings. Available software for the analysis of data from insulin pumps (Accu-Chek SmartPix Software, CarelinkPro, mylife Software) make it possible to assess what percentage of boluses calculated by BC is modified by the patient.

Another important issue with the use of $B C$ is the dosing of insulin for meals rich in proteins and fats. In the bolus calculators available on the market, it is not possible to separately enter information about the number of consumed protein-fat exchanges. The insulin dose can be increased by entering additional CEs or modified immediately after the BC calculation [20].

\section{Conclusions}

The bolus calculator is an indispensable tool in the treatment of type 1 diabetes mellitus with continuous subcutaneous insulin infusion. There is a lot of evidence for improving the quality of life and metabolic control of diabetes. It is recommended to use a BC from the beginning of therapy with PIP. Diabetes education and close cooperation with a diabetologist is necessary so that the patient knows how the bolus calculator works.

\section{Conflict of Interest}

UF received a lecture fee from Ypsomed. AG and DZZ participated in the Advisory Board for Medtronic, Roche Diagnostics and Ypsomed and received a lecture fee from Medtronic, Roche Diagnostics, and Ypsomed. AlA has received lecture fees from Medtronic, Roche Diagnostics, and Ypsomed. MM and AnA have received lecture fees from Ypsomed.

\section{REFERENCES}

1. Ramotowska A, Golicki D, Dżygało K, et al. The effect of using the insulin pump bolus calculator compared to standard insulin dosage calculations in patients with type 1 diabetes mellitus - systematic review. Exp Clin Endocrinol Diabetes. 2013; 121(5): 248-254, doi: 10.1055/s-0032-1331708, indexed in Pubmed: 23329581.

2. Boland EA, Grey M, Oesterle A, et al. Continuous subcutaneous insulin infusion. A new way to lower risk of severe hypoglycemia, improve metabolic control, and enhance coping in adolescents with type 1 diabetes. Diabetes Care. 1999; 22(11): 1779-1784, doi: 10.2337/diacare.22.11.1779, indexed in Pubmed: 10546007.

3. Linkeschova R, Raoul M, Bott U, et al. Less severe hypoglycaemia, better metabolic control, and improved quality of life in type 1 diabetes mellitus with continuous subcutaneous insulin infusion (CSII) therapy; an observational study of 100 consecutive 
patients followed for a mean of 2 years. Diabet Med. 2002; 19(9): 746-751, doi: 10.1046/j.1464-5491.2002.00713.x, indexed in Pubmed: 12207811.

4. Pozzilli P, Battelino T, Danne T, et al. Continuous subcutaneous insulin infusion in diabetes: patient populations, safety, efficacy, and pharmacoeconomics. Diabetes Metab Res Rev. 2016; 32(1): 21-39, doi: 10.1002/dmrr.2653, indexed in Pubmed: 25865292.

5. Araszkiewicz A, Bandurska-Stankiewicz E, Budzyński A, et al. 2020 Guidelines on the management of diabetic patients. A position of Diabetes Poland. Clin Diabetol. 2020; 9(1): 1-101.

6. Sussman A, Taylor EJ, Patel M, et al. Performance of a glucose meter with a built-in automated bolus calculator versus manual bolus calculation in insulin-using subjects. J Diabetes Sci Technol. 2012; 6(2): 339-344, doi: 10.1177/193229681200600218, indexed in Pubmed: 22538144.

7. Glaser NS, Iden SB, Green-Burgeson D, et al. Benefits of an insulin dosage calculation device for adolescents with type 1 diabetes mellitus. J Pediatr Endocrinol Metab. 2004; 17(12): 1641-1651, doi: 10.1515/jpem.2004.17.12.1641, indexed in Pubmed: 15645698.

8. Vallejo Mora MD, Carreira M, Anarte MT, et al. Bolus Calculator Reduces Hypoglycemia in the Short Term and Fear of Hypoglycemia in the Long Term in Subjects with Type 1 Diabetes (CBMDI Study). Diabetes Technol Ther. 2017; 19(7): 402-409, doi: 10.1089/ dia.2017.0019, indexed in Pubmed: 28594575.

9. Rabbone I, Scaramuzza AE, Ignaccolo MG, et al. Carbohydrate counting with an automated bolus calculator helps to improve glycaemic control in children with type 1 diabetes using multiple daily injection therapy: an 18-month observational study. Diabetes Res Clin Pract. 2014; 103(3): 388-394, doi: 10.1016/j. diabres.2013.12.026, indexed in Pubmed: 24447811.

10. Ehrmann D, Kulzer B, Schipfer M, et al. Efficacy of an Education Program for People With Diabetes and Insulin Pump Treatment (INPUT): Results From a Randomized Controlled Trial. Diabetes Care. 2018; 41(12): 2453-2462, doi: 10.2337/dc18-0917, indexed in Pubmed: 30305343.
11. Medtronic Diabetes | UK. Medtronic Diabetes. Accessed June 8, 2020. https://www.pompy-medtronic.pl/.

12. Pompy insulinowe | Polska. Accessed June 8, 2020. https://www. accu-chek.pl/pompy-insulinowe.

13. Pompa insulinowa mylife YpsoPump - mylife Polska ( $p l-P L)$. Accessed June 8, 2020. https://www.mylife-diabetescare.com/ pl-PL/produkty/systemy-infuzyjne/pompa-insulinowa-mylifeypsopump.html.

14. Thurm U, Gehr B. CGM- Und Insulinpumpenfibel: Bei Dir Piept's Ja! 3rd ed. Kirchheim; 2014.

15. Klupa T, Benbenek-Klupa T, Malecki M, et al. Clinical usefulness of a bolus calculator in maintaining normoglycaemia in active professional patients with type 1 diabetes treated with continuous subcutaneous insulin infusion. J Int Med Res. 2008; 36(5): 1112-1116, doi: 10.1177/147323000803600531, indexed in Pubmed: 18831908.

16. Evans M, Ceriello A, Danne T, et al. Use of fast-acting insulin aspart in insulin pump therapy in clinical practice. Diabetes Obes Metab. 2019; 21(9): 2039-2047, doi: 10.1111/dom.13798, indexed in Pubmed: 31144428.

17. Chetty T, Shetty V, Fournier PA, et al. Exercise management for young people with type 1 diabetes: a structured approach to the exercise consultation. Front Endocrinol (Lausanne). 2019; 10: 326, doi: 10.3389/fendo.2019.00326, indexed in Pubmed: 31258513.

18. Jarosz-Chobot P, Molęda P, Myśliwiec M, et al. Propozycja wstępnych ustawień kalkulatora bolusa systemu Accu-Chek Combo. Clin Diabetol. 2015; 4(B): 33-35.

19. Walsh J, Roberts R, Bailey T. Guidelines for optimal bolus calculator settings in adults. J Diabetes Sci Technol. 2011; 5(1): 129-135, doi: 10.1177/193229681100500118, indexed in Pubmed: 21303635.

20. Bell KJ, Smart CE, Steil GM, et al. Impact of fat, protein, and glycemic index on postprandial glucose control in type 1 diabetes: implications for intensive diabetes management in the continuous glucose monitoring era. Diabetes Care. 2015; 38(6): 1008-1015, doi: 10.2337/dc15-0100, indexed in Pubmed: 25998293. 